\title{
Hemodynamic Adaptation of Heart Failure to Percutaneous Venoarterial Extracorporeal Circulatory Supports
}

\author{
Pavel HÁLA ${ }^{1,2}$, Otomar KITTNAR ${ }^{1}$ \\ ${ }^{1}$ Department of Physiology, First Faculty of Medicine, Charles University, Prague, Czech Republic, \\ ${ }^{2}$ Department of Cardiology, Na Homolce Hospital, Prague, Czech Republic
}

Received September 27, 2019

Accepted June 30, 2020

Epub Ahead of Print September 9, 2020

\begin{abstract}
Summary
Extracorporeal life support (ECLS) is a treatment modality that provides prolonged blood circulation, gas exchange and can partially support or fully substitute functions of heart and lungs in patients with severe but potentially reversible cardiopulmonary failure refractory to conventional therapy. Due to high-volume bypass, the extracorporeal flow is interacting with native cardiac output. The pathophysiology of circulation and ECLS support reveals significant effects on arterial pressure waveforms, cardiac hemodynamics, and myocardial perfusion. Moreover, it is still subject of research, whether increasing stroke work caused by the extracorporeal flow is accompanied by adequate myocardial oxygen supply. The left ventricular (LV) pressure-volume mechanics are reflecting perfusion and loading conditions and these changes are dependent on the degree of the extracorporeal blood flow. By increasing the afterload, artificial circulation puts higher demands on heart work with increasing myocardial oxygen consumption. Further, this can lead to LV distention, pulmonary edema, and progression of heart failure. Multiple methods of LV decompression (atrial septostomy, active venting, intra-aortic balloon pump, pulsatility of flow) have been suggested to relieve LV overload but the main risk factors still remain unclear. In this context, it has been recommended to keep the rate of circulatory support as low as possible. Also, utilization of detailed hemodynamic monitoring has been suggested in order to avoid possible harm from excessive extracorporeal flow.
\end{abstract}

\section{Key words}

Extracorporeal membrane oxygenation - Heart failure • Hemodynamics • Ventricular overload • Perfusion

\section{Corresponding author}

P. Hála, Department of Physiology, First Faculty of Medicine, Charles University, Prague, Albertov 5, 12800 Prague 2, Czech Republic. E-mail: pavel.hala@hotmail.com

\section{Introduction}

Patients suffering of heart failure $(\mathrm{HF})$ require intensive and highly specialized management from the onset of disease. Despite of full supportive treatment, patient's hemodynamic status can change abruptly into acute decompensation of HF while causing a severe prognosis (Jackson et al. 2000). In situations when circulatory failure may not be possible to treat with conventional methods, extracorporeal life supports (ECLS) can temporarily substitute functions of heart and lungs and provide time for treatment of underlying condition (Abrams et al. 2014). These advantages in combination with ease of circuit introduction led to wide spread of ECLS for decompensated circulatory failure (Thiagarajan et al. 2017).

The artificial circuit can substitute the pump function of heart (Pranikoff et al. 1994, Combes et al. 2008), but due to changes in hemodynamics, its reinfusion flow to the arterial system increases afterload of left ventricle (LV), and thus puts higher demands on heart work (Seo et al. 1991, Burkhoff et al. 2015, Ostadal et al. 2015, Broome and Donker 2016, Hála et al. 2020). Further hemodynamic complications like LV dilation or pulmonary edema were described but their risk factors still remain unclear (Barbone et al. 2011, Soleimani and Pae 2012, Boulate et al. 2013). 
Therefore, detailed monitoring and better understanding of heart hemodynamics during ECLS might alleviate its negative impacts and improve prognosis (Soleimani and Pae 2012, Truby et al. 2017, Na et al. 2019). This review will focus on the current use and effects of ECLS during acute decompensation of HF and on available methods of hemodynamic assessment.

\section{Pathophysiology of HF}

The performance of the heart depends on the following components: stroke volume (SV; influenced by contractility, preload, and afterload) and heart rate. HF describes situations when the heart is unable to maintain adequate cardiac output (CO) to meet body requirements.

$\mathrm{HF}$ is a progressive disorder initiated after an index event with an abrupt, gradual, or insidious onset and a common corresponding classification distinguishes between acute and chronic forms. The HF syndrome can result from a decline in $\mathrm{SV}$ that is due to systolic dysfunction, diastolic dysfunction, or a combination of the two. Typically, causes for HF can be impaired myocardial work itself or can lie in its excessive volume or pressure overload, like in arterial hypertension or valvular disease.

With slow onset of advanced myocardial exhaustion pathways, increased afterload or preload can progress into reduction of $\mathrm{CO}$. This chronic course is then associated with prolonged neurohormonal activation (Floras 2009, Hartupee and Mann 2017) and allows to fully develop systemic adaptation mechanisms (Ošt'ádal and Vízek 2005). With rapid onset of the pathophysiological pathways, adaptation responses might be insufficient and acute cardiac decompensation may occur; in severe cases the circulatory failure can progress into cardiogenic shock with severe reduction in $\mathrm{CO}$ despite adequate ventricular filling.

In typical scenario of $\mathrm{HF}$ most prominent symptoms include dyspnea, fatigue, and lethargy as a consequence of tissue hypoperfusion. Fluid retention and capillary hydrodynamic pressure increase lead to edemas in predisposing tissues, effusions, and in severe cases to pulmonary edema. Physical signs include elevated jugular venous pressure, tachypnea, orthopnea, reduced exercise tolerance, pulmonary crepitation, swelling. With the progression to long-lasting HF, the continuing activation of neurohormonal and cytokine systems leads to vascular and left ventricular changes (Toischer et al. 2010).

\section{Interaction of cardiac and vascular changes}

Decreased cardiac output in HF leads to changes in intravascular volume, vascular resistance, and venous pressures. The interaction of cardiac and vascular changes can be examined in graph by using venous return curves and cardiac function curves (Guyton 1955) as presented in Figure 1A. Here, by equating corresponding curves, an equilibrium point of the $\mathrm{CO}$, venous return, and right atrial pressure is established. In heart failure, changes of preload help to mitigate the reduced cardiac performance (Borlaug and Kass 2008), however, elevation of the venous pressure can contribute to edemas. Moreover, concurrent systemic vasoconstriction adds to $\mathrm{LV}$ afterload, thus LV systolic ejection and cardiac output can be further depressed (Borlaug and Kass 2008, Marti et al. 2012). In addition, connecting an extracorporeal circulatory support changes the cardiac-vascular equilibrium by affecting both preload and afterload.
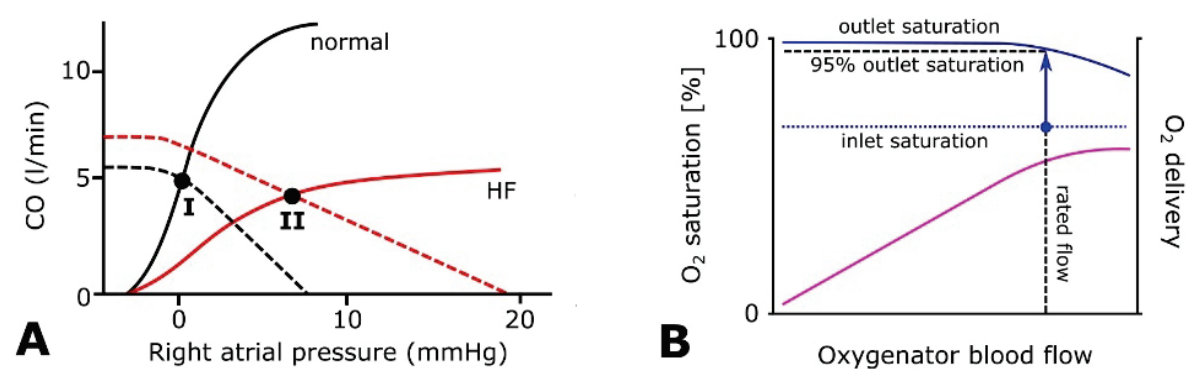

Fig. 1. (A) Schematics of cardiac output and venous return interactions. For normal heart (black) and for heart failure with reduced pumping effectivity (red) the cardiac output curves (solid lines) are intersecting with venous return curves (dashed lines) at marked equilibrium points (I and II). Each vascular curve intersects with $\mathrm{x}$-axis at the value of corresponding mean circulatory filling pressure and its slope reflects resistance to venous return. The marked equilibrium points allow to assess the cardiac output (CO), which is equal to the venous return, for normal circulation (point I) and for heart failure with activated adaptation of increased intravascular volume and resistance to venous return (point II). Adapted from Guyton (1955) and Klabunde (2012). (B) Concept of oxygenator "rated flow". Hyposaturated venous blood with $\mathrm{O}_{2}$ saturation of about $70 \%$ (blue dotted line) is passed through the gas exchange unit and exits at maximum saturation (blue solid line). Further increasing of the blood flow above certain point limits the maximum outflow saturation. The flow rate at which outlet saturation drops to $95 \%$ is described as "rated flow" (blue arrow), characterizes the capacity of each gas exchange unit, and limits its oxygen delivery (purple line). Adapted from Bartlett and Conrad (2017). 


\section{Compensatory mechanisms in HF}

If $\mathrm{CO}$ is reduced but allows temporary survival, series of compensatory adaptations are activated to maintain homeostasis and preserve systemic perfusion. These initially provide valuable support in order to mitigate the depressed hemodynamics by improving contraction and maintaining integrity of the circulation. But in cases of prolonged activation, their exhaustion or the intensification of their negative impacts result in a vicious cycle of circulatory decompensation. Consequent cardiogenic shock can lead to death if not adequately supported. Following compensatory mechanisms play important roles in HF pathophysiology.

\section{Sympathetic nervous system}

Early in the course, the sympathetic nervous system is quickly activated via chemo- and baroreceptors in an attempt to maintain CO (Floras 2009). Rise in plasma catecholamines (and concomitant withdrawal of the parasympathetic tone) leads to chronotropic stimulation and to increased force of contraction and vascular tone. Consequently, higher oxygen consumption is demanded by the myocardium, but the diastolic time shortens and limits the coronary perfusion. In long-term, chronic high catecholamine concentrations lead to down regulation of beta receptors on cardiomyocytes, so the sympathetic effects are attenuated and reduction in heart rate variability can be observed.

\section{Renin-angiotensin-aldosterone system}

Activation of this pathway occurs comparatively later in HF. Angiotensin II is a potent vasoconstrictor of renal efferent arterioles and systemic circulation. It also stimulates sympathetic but suppresses vagal tone, which contributes to endothelial dysfunction (Guang et al. 2012). Further, aldosterone effect on renal sodium reuptake add to extracellular fluid expansion, thus it elevates both ventricular filling pressures and afterload (Packer 1992).

\section{Natriuretic peptides}

Several natriuretic peptides, of similar structure, have been isolated and their function on the heart, kidneys, and nervous system described. Natriuretic peptides released from the atria and ventricles in response to wall stretch have main effects on natriuresis and vasodilation. Their concentration increase in response to volume expansion and physiologically mitigates the effects of angiotensin and aldosterone (Volpe et al. 2016).

\section{Other hormonal and non-hormonal mechanisms}

Antidiuretic hormone (vasopressin) concentrations are inappropriately high in both severe acute and chronic HF. It has a fluid retention effect and in high concentrations contributes to peripheral vasoconstriction typical for advanced HF. Several other molecules have been recognized to participate in the pathophysiology of HF. Endothelin is secreted by endothelial cells and acts as a potent vasoconstrictor. Up to some extent, this is opposed by endogenous nitric oxide, prostaglandins $\mathrm{E}_{2}$ and $\mathrm{I}_{2}$, or bradykinin from kallikrein-kinin system.

Lastly, the $\mathrm{CO}$ is modulated by non-hormonal cellular and hemodynamic mechanisms. Alterations in filling time and consequent changes in preload will effect the resultant inotropy. In addition, at increased heart rates, the higher aortic elastance will increase LV afterload and the phenomenon of force-frequency relationship will contribute to increased strength of myocardial contraction. However, in chronic course of HF this force-frequency relationship becomes blunted or even negative (Davies et al. 1995).

In summary, key neurohormonal systems maintain $\mathrm{CO}$ with an increase in heart rate, contractility, peripheral vasoconstriction, and increase in blood volume with retention of salt and water. Temporarily, compensatory mechanisms help for the cost of higher energy demands, but when persisting, the overexpression of biologically active molecules have detrimental effects on vascular compliance, heart remodeling, and systemic organs, which contributes to disease progression. On the other hand, when these mechanisms are not sufficient and fail, acute decompensation of HF occurs and requires immediate treatment.

\section{Acute management strategies}

Severe acute decompensation of HF represents a medical emergency requiring rapid initiation of therapy to provide symptom relief and identify and treat the etiological triggers. Generally, the therapy targets blood pressure, volume status, and end-organ perfusion. In case of systemic and pulmonary congestion, diuretics remain the cornerstone of therapy reducing excessive volume overload. In the absence of systemic hypotension, the combination with vasodilator agents, e.g. nitrates or nitroprusside, form the first line therapy to relieve 
symptoms and potentially increase cardiac output (Singh et al. 2017). Securing adequate oxygen saturation is necessary to prevent hypoxemia and its consequences like pulmonary arterial hypertension or even hypoxic cardiac arrest. The methods of oxygen therapy include adding oxygen to spontaneous ventilation by nasal cannulas or face masks, non-invasive and invasive mechanical ventilation.

In scenarios of patients presenting with profound systemic arterial hypotension and tissue hypoperfusion addition of inotropic agents and vasopressors must be considered to improve contractility and maintain vital organs perfusion. However, profound vasoconstriction elevates ventricular afterload and can further worsen peripheral oxygenation (Werdan et al. 2014). The added burden on the left ventricle then leads to increased stroke work, wall tension, and oxygen demands of the myocardium (Fuhrman et al. 1999).

When circulatory collapse is not responsive to compensatory mechanisms and provided treatment, mechanical circulatory supports, such as IABP, VAD, or ECMO, remain the ultimate modality to temporarily substitute heart or heart and lung functions. These are referred to as ECLS systems and provide time until recovery or decision about long-term therapy can be made. These systems underwent a massive development in recent decades and improved patients' prognosis. In emergency settings, devices allowing percutaneous access are preferable due to their fast initiation for bridging the patients over the critical period (Werdan et al. 2014).

\section{Heart failure models}

Modeling HF in experimental settings has been a common practice of research to understand hemodynamic effects of circulatory supports (Power and Tonkin 1999, Dixon and Spinale 2009) and multiple of these models have been used in combination with ECMO support (Rozencwajg et al. 2020). In general, the availability and variety of animal models used for hemodynamic studies are wide and offer choices for many specific needs. For such experiments, mostly porcine, canine, ovine or, with smaller settings, frequently murine models are chosen offering a good simulation of expected human body reactions (Power and Tonkin 1999). Furthermore, forms of single organ experiments (Trahanas et al. 2016, Church et al. 2017) or computer HF modeling (Broome and Donker 2016) are becoming more frequent for hemodynamic studies. To reliably mimic pathophysiology of HF, circulation is being artificially deteriorated. Damage to the heart can be caused by various tactics, often by one of ischemia, arrhythmia, pressure overload or cardiotoxic effects of drugs, any of these simulating the index event of HF pathophysiology and leading to hemodynamic deterioration of the model (Power and Tonkin 1999, Dixon and Spinale 2009, Ostadal et al. 2016, Lacko et al. 2018). To produce a true model of chronic HF, time has to be provided for developing the long-term adaptation of the whole organism, but advantages of such a model can offer fully developed compensatory mechanisms and form a suitable platform (Schmitto et al. 2010, Schmitto et al. 2011, Hala et al. 2018).

\section{ECLS}

\section{Definition of ECLS}

In order to maintain life in an organism with failing oxygen delivery, we need to support circulation, gas exchange, or both. ECLS is a treatment modality that provides prolonged blood circulation and gas exchange and can partially support or fully substitute functions of heart and lungs in patients with severe but potentially reversible cardiopulmonary failure refractory to conventional therapy. The system consists of intravascular cannulas connected to tubing set which is attached to mechanical pump. The extracorporeal circuit is then closed in a loop with a gas exchange unit, also called the artificial lung. Gas blender enables adjustment of the gas flow and oxygen fraction in the oxygenator. The functions of heart pump and lungs are transferred outside the body until the native organs recover. Due to this typical setting, ECLS is also referred to as extracorporeal membrane oxygenation (ECMO) and went through a thorough research and development in the last century. Although the main concepts remain, important improvements have been achieved, ECMO widespread globally, and its benefits are being applied in different fields of clinical and experimental medicine.

\section{ECMO configuration}

The ECMO system consists of multiple components, thus different settings of ECMO are available and can be applied to various disease conditions of cardiorespiratory systems. 


\section{Venovenous ECMO (VV ECMO)}

In $\mathrm{VV}$ ECMO, both drainage and reinfusion are located in veins. Either two separate cannulas or a single dual-lumen cannula can be introduced. Blood is usually drained from the common femoral vein and, after gas Exchange, reinfused to internal jugular or femoral vein. In this case, ECLS does not support the circulation, so the patient must have stable hemodynamics. VV ECMO is indicated in patients with respiratory failure.

\section{Venoarterial ECMO (VA ECMO)}

VA ECMO provides both respiratory and hemodynamic support; native and extracorporeal circuits are connected in parallel. Blood is being drained from right atrium or vena cava and reinfused to arterial system or aorta. The use of VA ECMO is well established and increasingly used in refractory cardiogenic shock due to postcardiotomy syndrome, myocardial infarction, fulminant myocarditis, or other myocardial pathologies, massive pulmonary embolism (Abrams et al. 2014), or during cardiac arrest (Swol et al. 2016). Technologically advanced pulsatile type of VA ECMO can improve some hemodynamic parameters in acute HF (Itoh et al. 2016, Ostadal et al. 2018).

\section{Venoarteriovenous ECMO (VAV ECMO)}

In situations of combined lung and heart failure, an additional reinfusion cannula is placed to the jugular vein. This setting provides oxygenated blood to pulmonary circulation and subsequently this blood is ejected by the LV and can perfuse coronary arteries.

\section{Arteriovenous ECMO (AV ECMO)}

Membrane lung can also be perfused from patient's arteries, fully avoiding blood pump. Its specific application is extracorporeal $\mathrm{CO}_{2}$ removal $\left(\mathrm{ECCO}_{2} \mathrm{R}\right)$ offering significant $\mathrm{CO}_{2}$ elimination and decreasing the need for mechanical ventilation (Brodie et al. 2019).

\section{Indications and survival of ECMO worldwide}

In general, the basic principles for providing ECMO are 1) reversible pathology which can be treated during the ECMO support and 2) the risks associated with ECMO are lower than those of not providing it (Robinson 2017). With different sizes of cannulas, tubing sets, pumps, and membrane lungs, ECMO serves in neonatal, pediatric, or adult patients, in whom multiple indications emerged during the years.

Indications for ECMO can be divided into three categories by the supported organ. Cardiac, respiratory, or the combination of the two. According to the data from the annual international ELSO Registry through January 2020, over total of 129,037 patients had received ECLS. The majority of patients were adult patients $45 \%, 33 \%$ were neonates, and $22 \%$ infants. The distribution of ECLS included $52 \%$ cases for respiratory failure, $36 \%$ cases for cardiac failure, and $12 \%$ cases for ECPR. Highest survival rate to discharge or transfer is steadily among neonatal ECMO population (66\%), followed by pediatric (54\%), and adult (49\%) patients (ELSO Registry Report 2020).

\section{Pathophysiology of VA ECMO}

To patients with severe cardiorespiratory failure, ECMO provides time to recover heart and lung functions but its technical nature also changes common physiological mechanisms. In further text, we provide a review of cardiopulmonary physiology, pathophysiology, and ECMO physiology related to mechanical replacement of heart and lung function.

\section{ECMO supplied oxygenation}

Blood oxygen content is the sum of oxygen bound to hemoglobin and oxygen dissolved. Oxygen delivery to tissues $\left(\mathrm{DO}_{2}\right)$ is than equal to the product of blood oxygen content and $\mathrm{CO}$. In a normal situation, resting $\mathrm{DO}_{2}$ is $600 \mathrm{ml} / \mathrm{min} / \mathrm{m}^{2}$, but the tissues consume $\left(\mathrm{VO}_{2}\right)$ only about $20 \%$ of the offered oxygen (Bartlett and Conrad 2017). That is why the mixed venous oxygen saturation remains high $(65-80 \%$, can vary according to metabolic rate). $\mathrm{DO}_{2}$ and $\mathrm{VO}_{2}$ variables are strongly affected by exercise, fever, other stress, catecholamine administration, respiration, $\mathrm{CO}$, or hemoglobin concentration. When oxygen extraction increases close to $50 \%$ (i.e. $\mathrm{DO}_{2} / \mathrm{VO}_{2}$ ratio approaches $2: 1$ ), tissues are not receiving enough oxygen to maintain aerobic metabolism. This situation intensifies anaerobic metabolism and the hemodynamic status becomes unsustainable if not adequately supported (Bartlett 2016).

The aim of patient management is to maintain $\mathrm{DO}_{2} / \mathrm{VO}_{2}$ ratio close to normal or at least above the critical 2:1. Use of ECLS is indicated in case of inadequate $\mathrm{DO}_{2}$ or when other interventions required are harmful (high dose vasopressors, high inspiratory 
pressures, high oxygen fraction) (Bartlett and Conrad 2017). ECMO circuit in its venoarterial form creates an extracorporeal bypass with gas exchange, and thus provides time for diagnosis and treatment while maintaining sufficient $\mathrm{DO}_{2}$.

\section{VA ECMO blood flow}

Blood pump generates the hydrodynamic force for the extracorporeal blood flow (EBF). The pressure has to push blood through the gas exchange unit, overcome all tubing and cannula resistances, and eject the blood back to the patient's circulation - against the aortic pressure. Importantly, most pump types create also negative pressure on the drainage site. If excessive, this suction is harmful to blood cells, so pressures no more negative than $-50 \mathrm{~mm} \mathrm{Hg}$ are targeted to prevent hemolysis or cavitation (Toomasian et al. 2017). Pumps can be of centrifugal, servo-modified roller, or peristaltic design. Worldwide, centrifugal pumps are most commonly used and apart from few experimental exceptions, ECMO flow is continuous with no or minimal pulse pressures. Introduction of new designs (head wash-out or bearing free magnetic levitation) in centrifugal pumps significantly reduced complications and allowed safer use (Lawson et al. 2008).

Choosing an appropriate flow range is of utmost importance for each individual patient. The pipe flow resistance depends on its length and the fourth power of its inner diameter, and thus in an ECMO circuit the cannula size is the main limiting factor of EBF (Montoya et al. 1991, Augustin et al. 2010), while blood viscosity being another independent parameter of flow. Variation of cannula sizes and designs have been introduced. Material engineering developed cannulas with thin but durable walls as kinking, chugging, and clot formation can strongly limit effectivity.

\section{ECMO gas exchange}

Gas exchange unit, also known as membrane or artificial lung or oxygenator, is the artificial organ where venous blood is being perfused through a dense grid of fibers filled with continuously blowing sweep gas. This gas can be pure oxygen or its mixture with air or $\mathrm{CO}_{2}$. Blood and gas are sealed, so they do not appear in direct contact (Kolobow and Bowman 1963). Gas exchange is based on the same principles of solubility, diffusibility, and partial pressure gradients as on the alveolocapillary membrane. In order to meet requirements, the gas exchange unit must be able to transfer the amount of oxygen consumed, as well as the amount of $\mathrm{CO}_{2}$ produced by the patient. The amount of gas exchange is a function of the membrane lung surface area, its permeance, and blood gas concentration gradients. Oxygen gradient is generally higher, but its diffusibility and solubility are lower compared to $\mathrm{CO}_{2} \cdot \mathrm{CO}_{2}$ clearance is managed by controlling the sweep gas flow; capacity of blood oxygenation of individual unit is described by the concept of "rated flow" - the maximum blood flow at which the venous blood is oxygenated to $95 \%$ (Fig. 1B) (Galletti et al. 1972). If water vapor condenses excessively on the membrane lung, gas exchange will be reduced a similarity to the pathophysiology of pulmonary edema. Current generation of centrifugal pumps, modern oxygenators, and biocompatible circuit materials significantly reduced problems commonly associated with older ECLS systems (Lequier et al. 2013).

\section{Monitoring of ECMO circuit}

Last, but important parts of every ECMO circuit are hemodynamic sensors for drainage and reinfusion cannulas, pre and post oxygenator pressure registering. Electricity supply, heat exchange unit, blood gas analysis, and clot recognition devices all help to adjust the circuit settings to achieve optimal performance.

\section{Complications of ECMO}

The benefits of ECMO must be weighed against possible risks as multiple complications have been associated with the use of ECMO. These events then participate on increased morbidity and mortality of ECMO treated patients (Abrams et al. 2014, Makdisi and Wang 2015).

\section{Bleeding and coagulopathies}

Commonly reported adverse events include significant bleeding. Even though bleeding is mostly located in cannulation sites and is associated with the necessary systemic anticoagulation, no universally accepted protocols are available and anticoagulation is being individualized (ELSO Guidelines 2013). In metaanalysis, the incidence of bleeding complications is reported to $>40 \%$ (Cheng et al. 2014). Heparin-induced thrombocytopenia and consumption of thrombocytes lead to reduced platelet count. Coagulation factors deficiencies (factor XIII, von Willebrand factor, and fibrinogen) 
appear important especially in long-term ECMO therapies (Makdisi and Wang 2015).

\section{Thrombosis}

Thrombosis incidence and the risk of thromboembolism are also increased with prolonged ECMO applications (Peek and Firmin 1999) as the blood contact to the foreign surface shifts the normal hemostatic balance and activates inflammatory response. Elevated pressure drop on the oxygenator and echocardiographic assessment can reveal potential clot formation in the circuit and heart. Prevention can be potentiated with anticoagulant-coated oxygenator and tubing surfaces or introducing nitric oxide into sweep gas (Major et al. 2014). Risk of ischemic stroke during VA ECMO is reported to $6 \%$ and its pathophysiology has been well documented in experiments (Janak et al. 2017).

\section{Limb ischemia and others}

Arterial occlusion distally to reinfusion cannula and subsequent limb ischemia occurs in around 10-20\% of cases and depends on the cannulation technic (Cheng et al. 2014). To prevent this complication, limb perfusion is ensured by additional sheath to the superficial femoral artery. Air embolism, hemolysis, and, more recently, complications associated with changes of hemodynamics have been described.

\section{Hemodynamics of VA ECMO}

As mentioned earlier, VA ECMO is an established method extensively being used to support circulation in the most severe conditions of HF decompensation like rapidly progressing cardiogenic shock or refractory cardiac arrest (Abrams et al. 2014, Werdan et al. 2014).

\section{Interaction of multiple circulations}

Unlikely to VV ECMO, the extracorporeal and native circulations in VA ECMO are connected in parallel. If some degree of $\mathrm{CO}$ is preserved, and thus the extracorporeal bypass is partial, both heart and ECMO are pumping blood into the aorta. Reinfused blood mixes in the aorta with left ventricular blood, which passed through the lungs. Therefore, the arterial blood is a combination of blood from these two sources (Bartlett and Conrad 2017) - aortic root is being filled antegradelly from the LV and descending aorta is receiving blood from the reinfusion cannula. The mixing site depends on the ratio of $\mathrm{CO}$ and EBF and on the position of reinfusion cannula tip (Kamimura et al. 1999).

If the site of mixing happens in the aortic arch or descending aorta, coronary circulation and carotid arteries receive blood that passed through the lungs and was ejected by the LV (Kinsella et al. 1992, Kamimura et al. 1999). In these situations, managing the lung ventilation is very important. If the lungs are working well, the LV ejects blood with optimal oxygen content. If the lungs are oxygenating poorly or not at all, the LV blood will have lower saturation. As a result, hypoxia of the tissues supplied by native CO may occur. This is called differential cyanosis or the Harlequin syndrome as the upper body parts are receiving less saturated blood. To prevent this severe condition of VAECMO in cardiorespiratory failure, additional reinfusion cannula is placed into the right atrium, forming a combination of venoarterial and venovenous ECMO circuits and providing oxygenated blood to the pulmonary circulation and subsequently to the LV and coronary arteries.

\section{Aortic pressure waveform}

Hemodynamic effects on the aortic pressure waveform depend on the portion of extracorporeal support. With $100 \%$ flow support, LV is not contributing to blood stream and pulse pressure becomes flat. In such a case all tissues are perfused by artificial circuit and if the heart valves are competent, blood stagnates in lungs and heart, producing risk for clot formation. Additionally, with no or severely limited heart ejection, LV gradually fills with blood causing the ventricular end-diastolic pressure to increase (Burkhoff et al. 2015). Aortic valve insufficiency can contribute to this phenomenon too (Sidebotham et al. 2012). With reducing the ECMO support and increasing the left ventricular contribution, pulse pressure increases. With support of $80 \%$, pulse pressure of about $10 \mathrm{~mm} \mathrm{Hg}$ is commonly observed (Bartlett and Conrad 2017), but effects of such pulsatility on microcirculation were insignificant in a small clinical study on post-cardiac arrest patients (Krupickova et al. 2017).

\section{Cardiac hemodynamics on VA ECMO}

VA ECMO supports systemic circulation by taking over part of cardiac workload, but it does not automatically reduce cardiac work (Fuhrman et al. 1999). 
Instead, reinfusion of blood from extracorporeal circuit increases systemic afterload. Especially with high EBF, this increase becomes significant and LV ejection is competing with higher aortic pressure (Shen et al. 2001). The impairment of cardiac performance with increased EBF during VA ECMO has been well documented in several experimental and clinical studies (Seo et al. 1991, Shen et al. 2001, Aissaoui et al. 2012, Ostadal et al. 2018, Hála et al. 2020).

Impaired contractility reduces ejection, ventricles retain blood and dilate. Thereby LV enddiastolic pressure and wall tension rises which relates to sarcomere stretch throughout the myocardium. The contractility force will increase according to the FrankStarling law, unless it becomes exhausted. In this setting, coronary perfusion may not keep pace with myocardial metabolic demands and initiates a vicious cycle.

To eject blood into the aorta, LV must exceed aortic diastolic pressure. If the LV is not capable of doing this, the aortic valve will not open. Although the heart would generate pressure, systemic arterial pressure trace will appear flat.

On the opposite side, right atrial pressure is reduced by draining blood into the venous cannula, decreasing ventricular preload (un-preloading of LV). This, by itself, improves organs perfusion at any aortic pressure. Draining the right heart should also reduce pulmonary artery pressure and allow remodeling of vascular smooth muscle (Fuhrman et al. 1999).

Left ventricular filling is resultant combination of multiple sources. Pulmonary veins are bringing blood from right heart ejection and bronchial circulation. Also Thebesian veins, aortic regurgitant flow, and flow through possible shunts are all contributing to the LV filling (Chung et al. 2014). At the moment when these sources outweigh LV ejection, further increase in end-diastolic pressure, left atrial hypertension, and heart chambers dilation have to be expected.

Theoretically, if heart retains enough power, it can compete with VA ECMO-caused afterload and no congestion is to be awaited. But, if the cardiac function is compromised, VA ECMO can progress to left atrial hypertension and pulmonary congestion even with venous cannula drainage.

\section{Progression to pulmonary congestion}

With progression of this pathophysiology, increased pressure propagates to the left atrium. Left atrial hypertension adds to risk of pulmonary congestion and possibly edema development. This feared complication of VA ECMO can lead to lung damage within hours. Regular monitoring of pulmonary capillary wedge pressure or imaging modalities can inform of venous congestion (Popková et al. 2020).

\section{Myocardial perfusion}

Myocardial oxygen demand is largely proportional to ventricular systolic pressure (Buckberg et al. 1972). Myocardial oxygen supply is directly proportional to coronary artery diastolic pressure and to duration of diastole (Brazier et al. 1974) and is inversely proportional to coronary sinus (subepicardial myocardium) and LV end-diastolic pressures (subendocardial myocardium) (Fuhrman et al. 1999). These are general rules, but with VA ECMO flow, their parameters are significantly altered.

In general, VA ECMO flow increases perfusion of all systemic tissues. Nevertheless, its effect on myocardial perfusion is yet unclear (Werdan et al. 2014). Aortic reinfusion increases the LV afterload associated with higher arterial blood pressure, and thus it impacts myocardial work. It is a subject of research whether increasing stroke work (SW) caused by extracorporeal flow is accompanied by adequate myocardial oxygen supply. It has been stated that as LV becomes distended, higher pressure is applied on the endocardial surface during diastole, potentially limiting perfusion of subendocardial myocardium (Kamimura et al. 1999).

On animal experiments higher VA ECMO flow was associated with lower coronary perfusion which was not accompanied by reduction of myocardial oxygen consumption (Kato et al. 1996). Even with low native CO and dominant VA ECMO flow, more than $90 \%$ of the coronary blood flow is distributed from the LV ejection (Kinsella et al. 1992) and in another study increase in coronary flow was observed with introduction of pulsatile form of VA ECMO (Cremers et al. 2015). Similarly, pulsatility of VA ECMO flow improved coronary perfusion in a model of hypoxemic acute $\mathrm{HF}$ at all degrees of circulatory support (Ostadal et al. 2018). On the other hand, another experimental study reported no increase in carotid or coronary perfusion with addition of IABP to VA ECMO, although providing pulsatility (Belohlavek et al. 2012). 


\section{Left ventricular mechanics}

By instantaneous measuring of pressure and cavitary volume, a typical pressure-volume (PV) loop depicts well ventricular mechanics of a single cardiac cycle. Under normal conditions, the PV loop is roughly trapezoidal, delimited by end-diastolic and end-systolic volume and pressure points (EDV, ESV, EDP, and ESP). Four sides connecting them then represent 1) isovolumic contraction; 2) ejection; 3) isovolumic relaxation; and 4) filling. Beginning after the isovolumic relaxation, LV volume starts to increase during diastole and becomes maximal at end-diastole. Then the isovolumic contraction begins, LV pressure exceeds aortic pressure, and blood is being ejected while the LV volume decreases until the aortic valve closes. SV is calculated as the width of the PV loop. Multiple load-dependent and load-independent indexes, like end-systolic and end-diastolic pressurevolume relationships (ESPVR and EDPVR), maximal positive pressure change $\left(\mathrm{dP} / \mathrm{dt}_{\max }\right)$, diastolic stiffness $(\mathrm{dP} / \mathrm{dV})$, and preload recruitable stroke work, can be calculated under various loading conditions. Without changes in contractile function and diastolic properties, PV loops will fit within the boundaries of ESPVR and EDPVR (Fig. 2B).

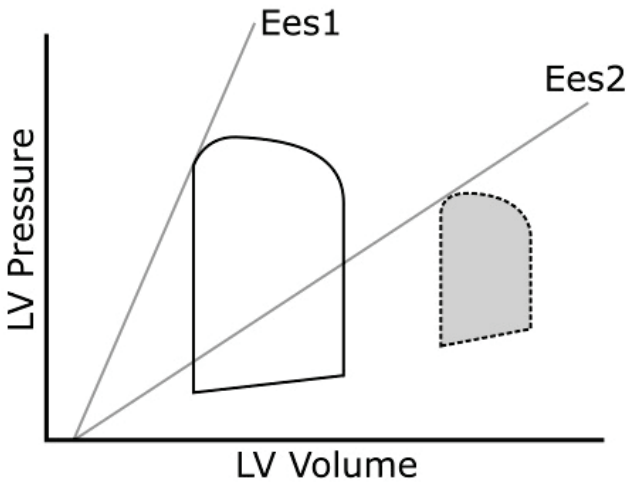

A Cardiogenic shock

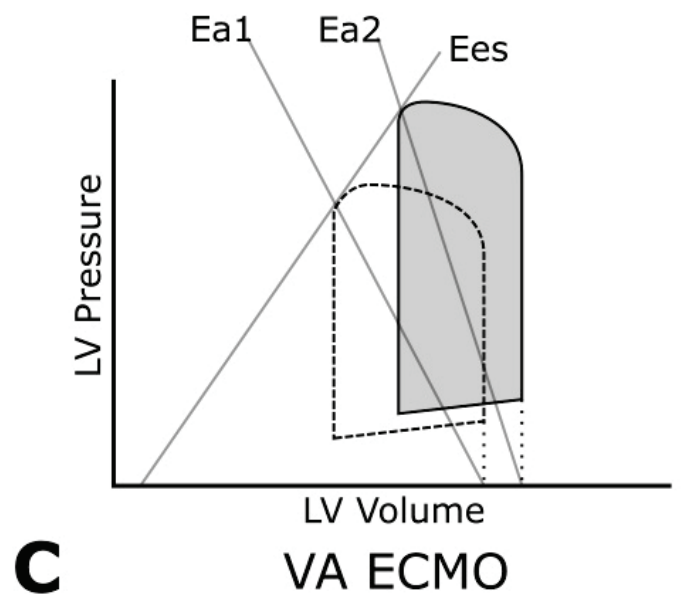

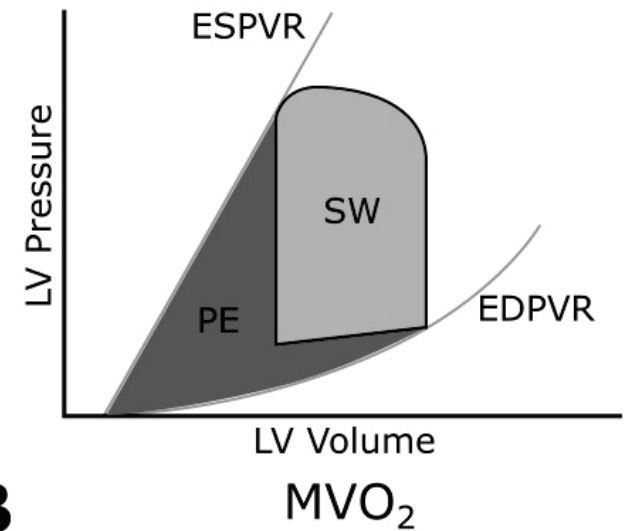

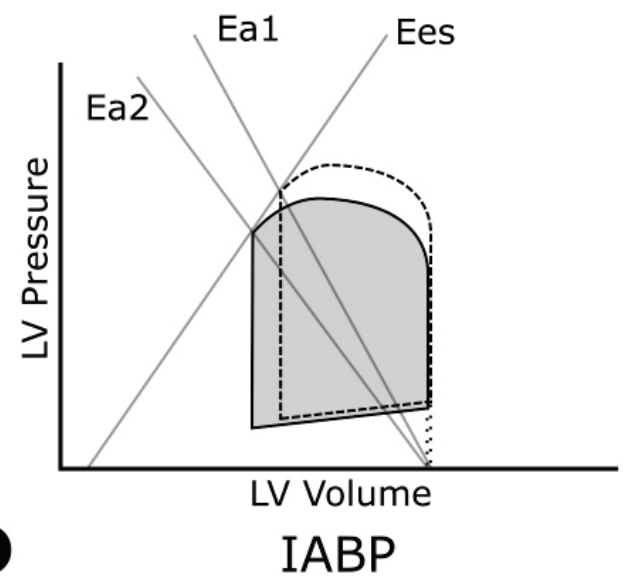

Fig. 2. (A) Normal PV loop (white) and PV loop in cardiogenic shock (dashed and gray); in cardiogenic shock end-systolic elastance is severely reduced (Ees2<Ees1), EDV and EDP are increased, SV reduced. (B) Myocardial oxygen consumption $\left(\mathrm{MVO}_{2}\right)$ is linearly correlated with pressure-volume loop area (PVA), which is the sum of the stroke work (SW) and the potential energy (PE). Bottom: Changes of cardiogenic shock PV loop (dashed) by effects of mechanical supports (gray). (C) VA ECMO increases afterload (Ea1<Ea2), reduces SV, and increases EDP and EDV. (D) Intraaortic balloon pump decreases afterload (Ea1>Ea2) and enhances LV ejection with higher stroke volume. Panel B adapted from Burkhoff et al. (2015), panel C adapted from Ostadal et al. (2015) and Hála et al. (2020), and panel D adapted from Rihal et al. (2015). 
Ventricular afterload is closely related to the vascular system characteristics against which the ventricle contracts (in figures depicted as $\mathrm{Ea}$ - effective arterial elastance); during VA ECMO support, this is strongly influenced by reinfusion blood flow.

$$
\mathrm{Ea}=\mathrm{ESP} / \mathrm{SV}
$$

The intercept of Ea and ESPVR then determines ventricular-vascular coupling, the concept of ventricular preload, afterload, contractility, and blood circulation relations. Specifically, SV can be estimated by the formula, where $\mathrm{V}_{0}$ is ESPVR volume axis intercept, and Ees is the slope of ESPVR:

$$
\mathrm{SV} \approx\left(\mathrm{EDV}-\mathrm{V}_{0}\right) /\left(1+\frac{\mathrm{Ea}}{\mathrm{Ees}}\right)
$$

LV stroke work can be calculated as the integral of left ventricular transmural pressure $(\mathrm{P})$ and cavitary volume (V) over each cardiac cycle as described by the formula:

$$
\mathrm{SW}=\int_{\mathrm{Vs}}^{\mathrm{Vd}} \mathrm{PdV}
$$

Where Vs and Vd are systolic and diastolic ventricular volumes, respectively. By definition, $\mathrm{SW}$ is depictured as the area encircled by PV loop. To reflect the heart frequency (HR) on myocardial demands, ventricular power output (VPO) can be calculated (Glower et al. 1985):

$$
\mathrm{VPO}=\mathrm{SW} * \mathrm{HR}
$$

Concept of PV loop also provides a platform to estimate myocardial oxygen consumption $\left(\mathrm{MVO}_{2}\right.$, Figure 2B) which is linearly related to sum of myocardial potential energy (PE) and SW (Suga 1979):

$$
\mathrm{MVO}_{2} \approx \text { constant } *(\mathrm{PE}+\mathrm{SW})
$$

With effects of VA ECMO cannulas suctioning and reinfusion of blood into the circulation, dramatic effects to LV hemodynamics are to be expected. Ventricular filling and peak pressures as well as contractility parameters are influenced by alterations in preload, afterload, and myocardial perfusion.

As VA ECMO reinfusion increases afterload, the Ea will increase, limiting the SV and increasing LV peak pressure (Fig. 2C). Depending on the resultant ventricular preloading and diastolic stiffness, the end-diastolic value of pressure and volume will shift the PV loop on the EDPVR curve. This is reflecting the LV distension reported in HF supported by VA ECMO (Burkhoff et al. 2015, Ostadal et al. 2015, Broome and Donker 2016,
Ostadal et al. 2018, Hála et al. 2020), although contradictive changes were reported by other authors Kawashima et al. 2011, Aissaoui et al. 2012, Rihal et al. 2015). Different degree of HF, rate of extracorporeal support, or methodology details may explain the discrepancies. Lastly, depending on how VA ECMO will affect coronary perfusion and myocardial energetics, Ees (i.e. the ESPVR slope) will also decrease and push the end-systolic point of PV loop rightward (Burkhoff et al. 2015, Rihal et al. 2015). Increase in myocardial PE and probably also in SW must then result in higher $\mathrm{MVO}_{2}$.

In a model of acute HF generated by hypoxic myocardial perfusion, Shen et al. (2001) reported decline of the contractility index $\mathrm{dP} / \mathrm{dt}_{\max }$ and $\mathrm{LV}$ peak pressure associated with VA ECMO flow, but in their settings all of the coronary vascular bed received hypoxemic blood.

In contrast, when the intra-aortic balloon pump is used, it reduces both the LV peak and end-diastolic pressures, and enhances ejection (Fig. 2D) (Werdan et al. 2014, Rihal et al. 2015).

These basic hemodynamic principles are also affected by other factors like 1) right-sided factors; 2) cardiovascular substrate - e.g. a history of chronic HF with dilated, remodeled $\mathrm{LV}$; or 3 ) the level of compensatory mechanisms. It is therefore important to distinguish between the primary hemodynamic effects of ECLS and the impact of secondary modulating factors invoked like changes in total peripheral vascular resistance and LV contractility (Burkhoff et al. 2015).

\section{Modeling the pathophysiology of ECMO circulation}

Experimental animal models have become an important tool for ECMO circulation research (Table 1). On variety of conditions (healthy circulation, acute or chronic HF, cardiac arrest) improvements of hemodynamic status have been demonstrated - increases in arterial pressures, tissue saturation, or resuscitability (Hala et al. 2016). But it has also been revealed, that the interaction of double circulations influences myocardial perfusion (Kato et al. 1996), blood flow distribution (Kinsella et al. 1992), and most interestingly also alterations of energetic demands on the heart muscle (Ostadal et al. 2015, Hála et al. 2020). As a result, an undesirable hemodynamic effect of excessive VA ECMO flow was postulated (Seo et al. 1991, Ostadal et al. 2015). 
Table 1. Review of hemodynamic studies on extracorporeal blood flow pathophysiology.

\begin{tabular}{|c|c|c|c|c|c|}
\hline & ECLS type & HF & Setting & Sample size & Assessed parameters/Main findings \\
\hline Hala et al. 2016 & Non-pulsatile & Chronic HF & $\begin{array}{l}\text { Experimental } \\
\text { (porcine) }\end{array}$ & 5 & $\begin{array}{l}\text { Perfusion and tissue oxygenation correlates } \\
\text { with EBF }\end{array}$ \\
\hline Hala et al. 2020 & Non-pulsatile & Chronic HF & $\begin{array}{l}\text { Experimental } \\
\text { (porcine) }\end{array}$ & 5 & EBF increases demands on LV work \\
\hline Ostadal et al. 2018 & Pulsatile & Acute HF & $\begin{array}{l}\text { Experimental } \\
\text { (porcine) }\end{array}$ & 16 & Pulsatile flow improves coronary perfusion \\
\hline Ostadal et al. 2015 & Non-pulsatile & Acute HF & $\begin{array}{l}\text { Experimental } \\
\text { (porcine) }\end{array}$ & 5 & Excessive EBF increases demands on LV \\
\hline Aissaoui et al. 2012 & Non-pulsatile & Mixed & clinical & 22 & $\begin{array}{c}\text { Echocardiographic Assessments, Tissue } \\
\text { Doppler }\end{array}$ \\
\hline Kato et al. 1996 & Non-pulsatile & - & $\begin{array}{l}\text { Experimental } \\
\text { (canine) }\end{array}$ & 14 & Coronary perfusion decreases with higher EBF \\
\hline Seo et al. 1991 & Non-pulsatile & - & $\begin{array}{l}\text { Experimental } \\
\text { (canine) }\end{array}$ & 16 & EDP increases with higher EBF \\
\hline Shen et al. 2001 & Non-pulsatile & - & $\begin{array}{l}\text { Experimental } \\
\text { (porcine) }\end{array}$ & 8 & $\begin{array}{l}\text { Intrinsic myocardial function is not reduced by } \\
\qquad \mathrm{EBF}\end{array}$ \\
\hline $\begin{array}{l}\text { Kawashima et al. } \\
2011\end{array}$ & Non-pulsatile & Acute HF & $\begin{array}{l}\text { Experimental } \\
\text { (canine) }\end{array}$ & 6 & $\begin{array}{l}\text { LV work with VA ECMO or Impella } 2.5 \\
\text { support }\end{array}$ \\
\hline Kinsela et al. 1992 & Non-pulsatile & - & $\begin{array}{l}\text { Experimental } \\
\text { (ovine) }\end{array}$ & 7 & $\begin{array}{c}>90 \% \text { of coronary flow originates from LV } \\
\text { ejection }\end{array}$ \\
\hline $\begin{array}{l}\text { Bèlohlávek et al. } \\
2012\end{array}$ & $\begin{array}{l}\text { (Non-) } \\
\text { pulsatile }\end{array}$ & Cardiac arrest & $\begin{array}{l}\text { Experimental } \\
\text { (porcine) }\end{array}$ & 11 & $\begin{array}{l}\text { IABP in VA ECMO worsens coronary } \\
\text { perfusion }\end{array}$ \\
\hline Cremers et al. 2015 & Pulsatile & Cardiac arrest & $\begin{array}{l}\text { Experimental } \\
\text { (porcine) }\end{array}$ & 8 & Pulsatile flow improves coronary perfusion \\
\hline Itoh et al. 2016 & Pulsatile & Cardiac arrest & $\begin{array}{l}\text { Experimental } \\
\text { (porcine) }\end{array}$ & 14 & Pulsatile flow improves brain saturation \\
\hline Popkova et al. 2020 & Non-pulsatile & Acute HF & $\begin{array}{l}\text { Experimental } \\
\text { (porcine) }\end{array}$ & 6 & $\begin{array}{c}\text { EBF reduces pulmonary electrical impedance } \\
\text { in HF }\end{array}$ \\
\hline
\end{tabular}

EBF - extracorporeal blood flow, LV - left ventricle, ECLS - extracorporeal life support, EDP - end-diastolic pressure, HF - heart failure, IABP - intra-aortic balloon pump.

Impacts of different levels of EBF on LV SW, mean arterial pressure, and coronary flow is well documented by review of related studies on acute and chronic HF (Table 2). In a recent study, our group demonstrated an increase of LV stroke work caused by increasing EBF of venoarterial ECMO in a porcine model of decompensated chronic HF (Hála et al. 2020). A graphical depiction of corresponding LV pressurevolume loop diagrams and how they develop with increasing EBF is shown in Figure 3. These stepwise increments in VA ECMO blood flow caused increases in both pressure and volume leading to LV dilation and higher energetic demands as the PV loop area shifts leftand upward and enlarges significantly. Similar experimental observations on pressure-volume LV characteristics were previously reported by Ostadal et al. (2015) on an acute porcine HF model, by Seo et al. (1991) on intact canine circulation, and predicted by mathematical modeling (Burkhoff et al. 2015, Broome and Donker 2016).

\section{Methods of LV decompression}

The use of VA ECMO in critically impaired heart function is associated with LV overload and dilation - when myocardial function cannot be instantly improved, left atrial hypertension escalates, and loss of arterial pulsation occurs. In such situations, several approaches have been suggested to decompress overloaded LV and decrease left atrial pressure (Soleimani and Pae 2012, Strunina and Ostadal 2016). Venting blood from the LV, atrium, or pulmonary artery then becomes a life-saving intervention (Fuhrman et al. 1999, Oštádal et al. 2018). If right heart is drained, lymphatic drainage should also be promoted (Fuhrman et al. 1999). 
Table 2. Hemodynamic effects of increasing VA ECMO flow - review of experimental studies. Main hemodynamic parameters are reported at stepwise degrees of VA ECMO support (degree $0-5$ ). HF - heart failure.

\begin{tabular}{|c|c|c|c|c|c|c|c|c|}
\hline & \multicolumn{8}{|c|}{ Degree of VA ECMO flow } \\
\hline & Notes & 0 & 1 & 2 & 3 & 4 & 5 & $\mathrm{P}$ \\
\hline \multicolumn{9}{|c|}{ Stroke work of left ventricle $\left[\mathrm{mm} \mathrm{Hg}^{*} \mathrm{ml}\right]$} \\
\hline Hala et al. 2016 & Chronic HF & $1434 \pm 941$ & $1595 \pm 987$ & $1867 \pm 1102$ & $2014 \pm 1062$ & $2105 \pm 1060$ & $1892 \pm 1036$ & $<0.05$ \\
\hline $\begin{array}{l}\text { Ostadal et al. } \\
2015\end{array}$ & Acute HF & - & $2096 \pm 342$ & $2510 \pm 335$ & $2752 \pm 346$ & $3031 \pm 404$ & $2884 \pm 412$ & $<0.001$ \\
\hline \multicolumn{9}{|c|}{ Mean arterial pressure [mm $\mathbf{H g}]$} \\
\hline Hala et al. 2016 & Chronic HF & $47 \pm 22$ & $56 \pm 20$ & $67 \pm 19$ & $75 \pm 16$ & $81 \pm 13$ & $84 \pm 12$ & $<0.001$ \\
\hline Kato et al. 1996 & $\begin{array}{c}\text { Normal heart } \\
\text { conditions }\end{array}$ & $84 \pm 24$ & $66 \pm 14$ & $68 \pm 14$ & $66 \pm 17$ & $66 \pm 18$ & $65 \pm 21$ & NS \\
\hline \multicolumn{9}{|c|}{ Coronary blood flow } \\
\hline Kato et al. 1996 & $\begin{array}{l}\text { Absolute } \\
{[\mathrm{ml} / \mathrm{min}]}\end{array}$ & $135 \pm 46$ & $106 \pm 26$ & $96 \pm 20$ & $89 \pm 22$ & $77 \pm 18$ & $71 \pm 17$ & $<0.01$ \\
\hline $\begin{array}{l}\text { Ostadal et al. } \\
2018\end{array}$ & $\begin{array}{c}\text { Relative to non- } \\
\text { pulsatile [\%] }\end{array}$ & - & $15.2 \pm 2.6$ & $17.0 \pm 2.7$ & $14.6 \pm 2.4$ & $7.8 \pm 2.4$ & - & $<0.05$ \\
\hline $\begin{array}{l}\text { Kinsela et al. } \\
1992\end{array}$ & $\begin{array}{c}\text { Absolute } \\
{[\mathrm{ml} / \mathrm{min} / 100 \mathrm{~g}]}\end{array}$ & $186 \pm 28$ & - & - & $253 \pm 44$ & - & $244 \pm 48$ & 0.46 \\
\hline
\end{tabular}

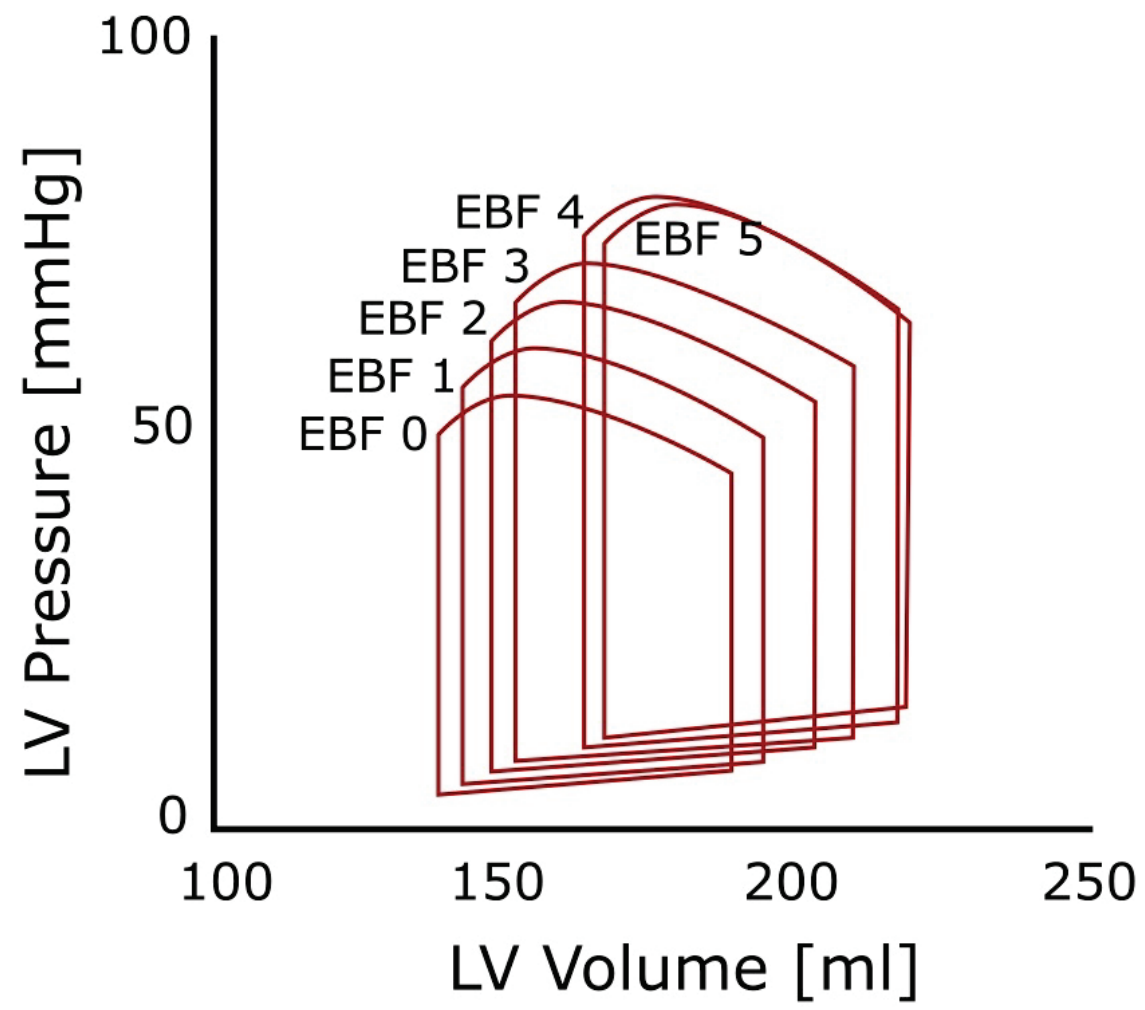

Fig. 3. Schematic mean PV loop changes by effects of increasing VA ECMO flow. The left ventricular volume, pressure, and work parameters in a porcine model of chronic heart failure reveal a dependence on VA ECMO flow (EBF in I/min). The stepwise increments in VA ECMO blood flow caused increases in both pressure and volume leading to LV dilation and higher energetic demands as the PV loop shifts left- and upward and its area enlarges significantly. Adapted from data by Hála et al. (2020). 


\section{Atrial septostomy}

Left-to-right shunt at atrial septal defect can effectively reduce the left atrial pressure. Artificial defect created by a blade and balloon atrial septostomy has also been reported to passively decompress the left atrium and LV and relieve pulmonary congestion (Seib et al. 1999). With size of atrial septal defect ranging between 2.5 and $8 \mathrm{~mm}$, left atrial pressure fell from 30.5 to $16 \mathrm{~mm} \mathrm{Hg}$ and the procedure was successful in all patients.

\section{Direct venting to reduce $L V$ filling pressures}

Surgical or mini-invasive transseptal introduction of venting cannula can be placed to left atrium or ventricle. Cannula is then connected to the drainage site of ECMO circuit and with active suction limits ventricular overload. With the advantage of transesophageal echocardiography guidance, the left atrial cannula can be inserted during ongoing ECMO therapy (Strunina and Ostadal 2016). Direct LV venting can be done by placing a transaortic cannula or a pigtail catheter. Successful cases were reported by Barbone (2011) and Fumagalli (2004). Alternatively, an additional cannula can be inserted percutaneously into the pulmonary artery and connected to the ECMO drainage tubing (Kolobow et al. 1988, Avalli et al. 2011, Fouilloux et al. 2011, Donker et al. 2019).

\section{Intra-aortic balloon pump}

Decompression of left-sided chambers can be also achieved by intra-aortic balloon pump (IABP). Rapid ECG-triggered inflation-deflation of this minimally invasive balloon in the descending aorta offers a passive reduction of LV afterload, facilitates ejection, and increases diastolic blood pressure (Kawashima et al. 2011, Rihal et al. 2015). Hydrostatic pulmonary edema prevention, modest changes in $\mathrm{SV}, \mathrm{CO}$, and coronary and peripheral perfusion, as well as improved survival in part of clinical studies have all been described (Doll et al. 2004, Belohlavek et al. 2012, Werdan et al. 2014, Brechot et al. 2018), but the risks and benefits of combined IABP and ECMO are still being debated (Swol et al. 2016).

\section{Percutaneous LV support or assist device}

Insertion of a microaxial rotary pump during VA ECMO therapy reduces the LV filling pressure (Kawashima et al. 2011, Koeckert et al. 2011). This combination can improve hemodynamic status by active blood suction from LV cavity directly to the ascending aorta. Implantation of LV assist device (VAD) requires open chest surgery and can be used for long-term or even destination therapy, but is not suitable in an acute presentation of cardiogenic shock (Werdan et al. 2014).

\section{Conclusions}

Circulatory decompensation which developed on grounds of heart failure represents a severe condition that requires intensive treatment. When the physiological compensatory mechanisms with conventional therapy approaches are insufficient to revert failing hemodynamics, ECMO systems can serve as extracorporeal circulatory support.

In cases of potentially reversible underlying disease, the ECMO in venoarterial setting can substitute pump function of heart as well as gas exchange. The relatively easy and prompt percutaneous ECMO introduction led to widespread of its use with large impact on patients' outcome.

The pathophysiological consequences of ECMO are complex and include blood interaction with the foreign surface materials, blood gases transfers, and hydrodynamic changes caused by drainage, reinfusion, and alterations of heart work. The VA ECMO circuit is set in parallel with the native cardiac output and the reinfusion flow is increasing LV afterload. The interactions of these two circulations are defined by changes in pressures, flows, and overall impact on the hemodynamics.

As mentioned in this review, these effects have been demonstrated in a number of clinical and experimental studies. Recently, increases in LV pressures, volumes, and stroke work have been reported with higher rates of EBF. Whether the myocardial perfusion and oxygen supply can keep pace with the increasing energetic demands, remains unclear, and thus these observations imply that excessive ECMO blood flow can be harmful. If submaximal flows can provide hemodynamic support and adequate gas exchange, high rates of EBF may not only be unnecessary but also detrimental to ventricular overload. Moreover, all mentioned methods of LV decompression are invasive, some requiring surgical approach, others being introduced percutaneously, and thus significantly increase the risks of ECMO complications. A conservative approach would be reducing the EBF as low as possible while still maintaining adequate tissue oxygenation.

According to current opinions, decreasing the 
VA ECMO support to the minimal EBF rate necessary for tissue perfusion has been advised in situations of decompensated HF, but the optimal level of EBF remain unknown in specific situations like acute HF or profound decompensation of chronic HF with fully developed compensatory mechanisms. Detailed monitoring of the heart hemodynamics, e.g. by assessing the pulmonary circulation or ventricular pressure-volume characteristics, may help in these decisions. Considering the experimental results, we propose that to decrease the risk of LV overload, VA ECMO flow should be maintained at the lowest level securing adequate tissue perfusion.

\section{Conflict of Interest}

There is no conflict of interest.

\section{Acknowledgements}

This review is part of the author's dissertation thesis and its publication was supported by GACR 20-25429S and MH CZ - DRO (NNH, 00023884), IG200501.

\section{Abbreviations}

$\mathrm{CO}$ - cardiac output, $\mathrm{dP} / \mathrm{dt}_{\max }-$ maximal positive pressure change, $\mathrm{dP} / \mathrm{dV}$ - diastolic stiffness, Ea effective arterial elastance, EBF - extracorporeal blood flow, ECLS - extracorporeal life support, ECMO extracorporeal membrane oxygenation, EDP, ESP - enddiastolic and end-systolic pressure, EDV, ESV - enddiastolic and end-systolic volume, Ees - slope of ESPVR, ESPVR and EDPVR - end-systolic and end-diastolic pressure-volume relationship, HF - heart failure, HR heart rate, IABP - intra-aortic balloon pump, LV - left ventricle, $\mathrm{VAD}$ - ventricular assist device, $\mathrm{MVO}_{2}-$ myocardial oxygen consumption, PE - myocardial potential energy, PV (loop) - pressure-volume (loop), $\mathrm{rSO}_{2}$ - regional tissue oxygenation, $\mathrm{SvO}_{2}-$ mixed venous blood saturation, $\mathrm{SV}$ - stroke volume, $\mathrm{SW}$ - stroke work, VPO - ventricular power output.

\section{References}

ABRAMS D, COMBES A, BRODIE D: Extracorporeal membrane oxygenation in cardiopulmonary disease in adults. J Am Coll Cardiol 63: 2769-2778, 2014. https://doi.org/10.1016/j.jacc.2014.03.046

AISSAOUI N, GUEROT E, COMBES A, DELOUCHE A, CHASTRE J, LEPRINCE P, LEGER P, DIEHL JL, FAGON JY, DIEBOLD B: Two-dimensional strain rate and Doppler tissue myocardial velocities: analysis by echocardiography of hemodynamic and functional changes of the failed left ventricle during different degrees of extracorporeal life support. J Am Soc Echocardiogr 25: 632-640, 2012. https://doi.org/10.1016/j.echo.2012.02.009

AUGUSTIN S, HORTON A, BUTT W, BENNETT M, HORTON S: Centrifugal pump inlet pressure site affects measurement. Perfusion 25: 313-320, 2010. https://doi.org/10.1177/0267659110376697

AVAlli L, MAGGiOni E, SANGALli F, FAVINI G, FORMiCA F, FUMAGALLI R: Percutaneous left-heart decompression during extracorporeal membrane oxygenation: an alternative to surgical and transeptal venting in adult patients. ASAIO J 57: 38-40, 2011. https://doi.org/10.1097/mat.0b013e3181fe5d0b

BARBONE A, MALVINDI PG, FERRARA P, TARELLI G: Left ventricle unloading by percutaneous pigtail during extracorporeal membrane oxygenation. Interact Cardiovasc Thorac Surg 13: 293-295, 2011. https://doi.org/10.1510/icvts.2011.269795

BARTLETT RH: Physiology of gas exchange during ECMO for respiratory failure. J Intensive Care Med 32: 243-248, 2016. https://doi.org/10.1177/0885066616641383

BARTLETT RH, CONRAD SA: The physiology of extracorporeal life support. In: Extracorporeal Life Support: The ELSO Red Book (5th Edition). BROGAN TV, LEQUIER L, LORUSSO R, MACLAREN G, PEEK G (eds), Ann Arbor, MI, ELSO, 2017, pp 31-47.

BELOHLAVEK J, MLCEK M, HUPTYCH M, SVOBODA T, HAVRANEK S, OST'ADAL P, BOUCEK T, KOVARNIK T, MLEJNSKY F, MRAZEK V, BELOHLAVEK M, ASCHERMANN M, LINHART A, KITTNAR O: Coronary versus carotid blood flow and coronary perfusion pressure in a pig model of prolonged cardiac arrest treated by different modes of venoarterial ECMO and intraaortic balloon counterpulsation. Crit Care 16: R50, 2012. https://doi.org/10.1186/cc11254 
BORLAUG BA, KASS DA: Ventricular-vascular interaction in heart failure. Heart Fail Clin 4: 23-36, 2008. https://doi.org/10.1016/j.hfc.2007.10.001

BOULATE D, LUYT CE, POZZI M, NICULESCU M, COMBES A, LEPRINCE P, KIRSCH M: Acute lung injury after mechanical circulatory support implantation in patients on extracorporeal life support: an unrecognized problem. Eur J Cardiothorac Surg 44: 544-549; discussion 549-550, 2013. https://doi.org/10.1093/ejcts/ezt125

BRAZIER J, COOPER N, BUCKBERG G: The adequacy of subendocardial oxygen delivery: the interaction of determinants of flow, arterial oxygen content and myocardial oxygen need. Circulation 49: 968-977, 1974. https://doi.org/10.1161/01.cir.49.5.968

BRECHOT N, DEMONDION P, SANTI F, LEBRETON G, PHAM T, DALAKIDIS A, GAMBOTTI L, LUYT CE, SCHMIDT M, HEKIMIAN G, CLUZEL P, CHASTRE J, LEPRINCE P, COMBES A: Intra-aortic balloon pump protects against hydrostatic pulmonary oedema during peripheral venoarterial-extracorporeal membrane oxygenation. Eur Heart J Acute Cardiovasc Care 7: 62-69, 2018. https://doi.org/10.1177/2048872617711169

BRODIE D, SLUTSKY AS, COMBES A: Extracorporeal life support for adults with respiratory failure and related indications: A review. JAMA 322: 557-568, 2019. https://doi.org/10.1001/jama.2019.9302

BROOME M, DONKER DW: Individualized real-time clinical decision support to monitor cardiac loading during venoarterial ECMO. J Transl Med 14: 4, 2016. https://doi.org/10.1186/s12967-015-0760-1

BUCKBERG GD, FIXLER DE, ARCHIE JP, HOFFMAN JI: Experimental subendocardial ischemia in dogs with normal coronary arteries. Circ Res 30: 67-81, 1972. https://doi.org/10.1161/01.res.30.1.67

BURKHOFF D, SAYER G, DOSHI D, URIEL N: Hemodynamics of mechanical circulatory support. J Am Coll Cardiol 66: 2663-2674, 2015. https://doi.org/10.1016/j.jacc.2015.10.017

CHENG R, HACHAMOVITCH R, KITTLESON M, PATEL J, ARABIA F, MORIGUCHI J, ESMAILIAN F, AZARBAL B: Complications of extracorporeal membrane oxygenation for treatment of cardiogenic shock and cardiac arrest: a meta-analysis of 1,866 adult patients. Ann Thorac Surg 97: 610-616, 2014. https://doi.org/10.1016/j.athoracsur.2013.09.008

CHUNG M, SHILOH AL, CARLESE A: Monitoring of the adult patient on venoarterial extracorporeal membrane oxygenation. ScientificWorldJournal 2014: 393258, 2014. https://doi.org/10.1155/2014/393258

CHURCH JT, ALGHANEM F, DEATRICK KB, TRAHANAS JM, PHILLIPS JP, HEE SONG M, PERKINS EM, BARTLETT RH, ROJAS-PENA A, BOCKS ML, OWENS GE: Normothermic ex vivo heart perfusion: effects of live animal blood and plasma cross circulation. ASAIO J 63: 766-773, 2017. https://doi.org/10.1097/mat.0000000000000583

COMBES A, LEPRINCE P, LUYT CE, BONNET N, TROUILLET JL, LEGER P, PAVIE A, CHASTRE J: Outcomes and long-term quality-of-life of patients supported by extracorporeal membrane oxygenation for refractory cardiogenic shock. Crit Care Med 36: 1404-1411, 2008. https://doi.org/10.1097/ccm.0b013e31816f7cf7

CREMERS B, LINK A, WERNER C, GORHAN H, SIMUNDIC I, MATHEIS G, SCHELLER B, BOHM M, LAUFS U: Pulsatile venoarterial perfusion using a novel synchronized cardiac assist device augments coronary artery blood flow during ventricular fibrillation. Artif Organs 39: 77-82, 2015. https://doi.org/10.1111/aor.12413

DAVIES CH, DAVIA K, BENNETT JG, PEPPER JR, POOLE-WILSON PA, HARDING SE: Reduced contraction and altered frequency response of isolated ventricular myocytes from patients with heart failure. Circulation 92: 2540-2549, 1995. https://doi.org/10.1161/01.cir.92.9.2540

DIXON JA, SPINALE FG: Large animal models of heart failure: a critical link in the translation of basic science to clinical practice. Circ Heart Fail 2: 262-271, 2009. https://doi.org/10.1161/circheartfailure.108.814459

DOLL N, KIAII B, BORGER M, BUCERIUS J, KRAMER K, SCHMITT DV, WALTHER T, MOHR FW: Five-year results of 219 consecutive patients treated with extracorporeal membrane oxygenation for refractory postoperative cardiogenic shock. Ann Thorac Surg 77: 151-157; discussion 157, 2004. https://doi.org/10.1016/s0003-4975(03)01329-8

DONKER DW, BRODIE D, HENRIQUES JPS, BROOME M: Left ventricular unloading during veno-arterial ECMO: A review of percutaneous and surgical unloading interventions. Perfusion 34: 98-105, 2019. https://doi.org/10.1177/0267659118794112

ELSO Guidelines for Cardiopulmonary Extracorporeal Life Support, Version 1.3. November 2013. Ann Arbor, MI, USA, 2013. 
FLORAS JS: Sympathetic nervous system activation in human heart failure: clinical implications of an updated model. J Am Coll Cardiol 54: 375-385, 2009. https://doi.org/10.1016/j.jacc.2009.03.061

FOUILLOUX V, LEBRUN L, MACE L, KREITMANN B: Extracorporeal membranous oxygenation and left atrial decompression: a fast and minimally invasive approach. Ann Thorac Surg 91: 1996-1997, 2011. https://doi.org/10.1016/j.athoracsur.2011.01.005

FUHRMAN BP, HERNAN LJ, ROTTA AT, HEARD CM, ROSENKRANZ ER: Pathophysiology of cardiac extracorporeal membrane oxygenation. Artif Organs 23: 966-969, 1999. https://doi.org/10.1046/j.15251594.1999.06484.X

FUMAGALLI R, BOMBINO M, BORELLI M, ROSSI F, COLOMBO V, OSCULATI G, FERRAZZI P, PESENTI A, GATTINONI L: Percutaneous bridge to heart transplantation by venoarterial ECMO and transaortic left ventricular venting. Int J Artif Organs 27: 410-413, 2004. https://doi.org/10.1177/039139880402700510

GALLETTI PM, RICHARDSON PD, SNIDER MT, FRIEDMAN LI: A standardized method for defining the overall gas transfer performance of artificial lungs. Trans Am Soc Artif Intern Organs 18: 359-368, 374, 1972. https://doi.org/10.1097/00002480-197201000-00090

GLOWER DD, SPRATT JA, SNOW ND, KABAS JS, DAVIS JW, OLSEN CO, TYSON GS, SABISTON DC JR, RANKIN JS: Linearity of the Frank-Starling relationship in the intact heart: the concept of preload recruitable stroke work. Circulation 71: 994-1009, 1985. https://doi.org/10.1161/01.cir.71.5.994

GUANG C, PHILLIPS RD, JIANG B, MILANI F: Three key proteases--angiotensin-I-converting enzyme (ACE), ACE2 and renin--within and beyond the renin-angiotensin system. Arch Cardiovasc Dis 105: 373-385, 2012. https://doi.org/10.1016/j.acvd.2012.02.010

GUYTON AC: Determination of cardiac output by equating venous return curves with cardiac response curves. Physiol Rev 35: 123-129, 1955. https://doi.org/10.1152/physrev.1955.35.1.123

HALA P, MLCEK M, OSTADAL P, JANAK D, POPKOVA M, BOUCEK T, LACKO S, KUDLICKA J, NEUZIL P, KITTNAR O: Regional tissue oximetry reflects changes in arterial flow in porcine chronic heart failure treated with venoarterial extracorporeal membrane oxygenation. Physiol Res 65 (Suppl 5): S621-S631, 2016. https://doi.org/10.33549/physiolres.933532

HALA P, MLCEK M, OSTADAL P, JANAK D, POPKOVA M, BOUCEK T, LACKO S, KUDLICKA J, NEUZIL P, KITTNAR O: Tachycardia-induced cardiomyopathy as a chronic heart failure model in swine. J Vis Exp 132: 57030, 2018. https://doi.org/10.3791/57030

HÁLA P, MLČEK M, OŠŤÁDAL P, POPKOVÁ M, JANÁK D, BOUČEK T, LACKO S, KUDLIČKA J, NEUŽIL P, KITTNAR O: Increasing venoarterial extracorporeal membrane oxygenation flow puts higher demands on left ventricular work in a porcine model of chronic heart failure. J Transl Med 18: 75, 2020. https://doi.org/10.1186/s12967-020-02250-x

HARTUPEE J, MANN DL: Neurohormonal activation in heart failure with reduced ejection fraction. Nat Rev Cardiol 14: 30-38, 2017. https://doi.org/10.1038/nrcardio.2016.163

ITOH H, ICHIBA S, UJIKE Y, DOUGUCHI T, OBATA H, INAMORI S, IWASAKI T, KASAHARA S, SANO S, UNDAR A: Effect of the pulsatile extracorporeal membrane oxygenation on hemodynamic energy and systemic microcirculation in a piglet model of acute cardiac failure. Artif Organs 40: 19-26, 2016. https://doi.org/10.1111/aor.12588

JACKSON G, GIBBS CR, DAVIES MK, LIP GY: ABC of heart failure. Pathophysiology. BMJ 320: 167-170, 2000. https://doi.org/10.1136/bmj.320.7228.167

JANAK D, HALA P, MLCEK M, POPKOVA M, LACKO S, KUDLICKA J, KITTNAR O: Detection of microembolic signals in the common carotid artery using Doppler sonography in the porcine model of acute heart failure treated by veno-arterial extracorporeal membrane oxygenation. Physiol Res 66 (Suppl 4): S529-S536, 2017. https://doi.org/10.33549/physiolres.933806

KAMIMURA T, SAKAMOTO H, MISUMI K: Regional blood flow distribution from the proximal arterial cannula during veno-arterial extracorporeal membrane oxygenation in neonatal dog. J Vet Med Sci 61: 311-315, 1999. https://doi.org/10.1292/jvms.61.311 
KATO J, SEO T, ANDO H, TAKAGI H, ITO T: Coronary arterial perfusion during venoarterial extracorporeal membrane oxygenation. J Thorac Cardiovasc Surg 111: 630-636, 1996. https://doi.org/10.1016/s0022$\underline{5223(96) 70315-X}$

KAWASHIMA D, GOJO S, NISHIMURA T, ITODA Y, KITAHORI K, MOTOMURA N, MOROTA T, MURAKAMI A, TAKAMOTO S, KYO S, ONO M: Left ventricular mechanical support with Impella provides more ventricular unloading in heart failure than extracorporeal membrane oxygenation. ASAIO J 57: 169-176, 2011. https://doi.org/10.1097/mat.0b013e31820e121c

KINSELLA JP, GERSTMANN DR, ROSENBERG AA: The effect of extracorporeal membrane oxygenation on coronary perfusion and regional blood flow distribution. Pediatr Res 31: 80-84, 1992. https://doi.org/10.1203/00006450-199201000-00015

KLABUNDE RE: Cardiovascular Physiology Concepts (2nd Edition). Baltimore, MD, USA, Lippincott Williams \& Wilkins, 2012, 256 p.

KOECKERT MS, JORDE UP, NAKA Y, MOSES JW, TAKAYAMA H: Impella LP 2.5 for left ventricular unloading during venoarterial extracorporeal membrane oxygenation support. J Card Surg 26: 666-668, 2011. https://doi.org/10.1111/j.1540-8191.2011.01338.x

KOLOBOW T, BOWMAN RL: Construction and evaluation of an alveolar membrane artificial heart-lung. Trans Am Soc Artif Intern Organs 9: 238-243, 1963.

KOLOBOW T, ROSSI F, BORELLI M, FOTI G: Long-term closed chest partial and total cardiopulmonary bypass by peripheral cannulation for severe right and/or left ventricular failure, including ventricular fibrillation. The use of a percutaneous spring in the pulmonary artery position to decompress the left heart. ASAIO Trans 34: 485-489, 1988. https://doi.org/10.1097/00002480-199711000-00015

KRUPICKOVA P, HUPTYCH M, MORMANOVA Z, BOUCEK T, BELZA T, SMID O, KRAL A, SKALICKA H, LINHART A, BELOHLAVEK J: Effect of pulsatility on microcirculation in patients treated with extracorporeal cardiopulmonary resuscitation: a pilot study. ASAIO J 63: 386-391, 2017. https://doi.org/10.1097/mat.0000000000000492

LACKO S, MLCEK M, HALA P, POPKOVA M, JANAK D, HRACHOVINA M, KUDLICKA J, HRACHOVINA V, OSTADAL P, KITTNAR O: Severe acute heart failure - experimental model with very low mortality. Physiol Res 67: 555-562, 2018. https://doi.org/10.33549/physiolres.933774

LAWSON DS, LAWSON AF, WALCZAK R, MCROBB C, MCDERMOTT P, SHEARER IR, LODGE A, JAGGERS J: North American neonatal extracorporeal membrane oxygenation (ECMO) devices and team roles: 2008 survey results of Extracorporeal Life Support Organization (ELSO) centers. J Extra Corpor Technol 40: 166-174, 2008. https://doi.org/10.1191/0267659105pf819oa

LEQUIER L, HORTON SB, MCMULLAN DM, BARTLETT RH: Extracorporeal membrane oxygenation circuitry. Pediatr Crit Care Med 14 (Suppl 1): S7-S12, 2013. https://doi.org/10.1097/pcc.0b013e318292dd10

MAJOR TC, HANDA H, ANNICH GM, BARTLETT RH: Development and hemocompatibility testing of nitric oxide releasing polymers using a rabbit model of thrombogenicity. J Biomater Appl 29: 479-501, 2014. https://doi.org/10.1177/0885328214538866

MAKDISI G, WANG IW: Extra corporeal membrane oxygenation (ECMO) review of a lifesaving technology. J Thorac Dis 7: E166-E176, 2015. https://doi.org/10.3978/j.issn.2072-1439.2015.07.17

MARTI CN, GHEORGHIADE M, KALOGEROPOULOS AP, GEORGIOPOULOU VV, QUYYUMI AA, BUTLER J: Endothelial dysfunction, arterial stiffness, and heart failure. J Am Coll Cardiol 60: 1455-1469, 2012. https://doi.org/10.1016/j.jacc.2011.11.082

MONTOYA JP, MERZ SI, BARTLETT RH: A standardized system for describing flow/pressure relationships in vascular access devices. ASAIO Trans 37: 4-8, 1991. https://doi.org/10.1097/00002216-199101000-00003

NA SJ, YANG JH, YANG JH, SUNG K, CHOI JO, HAHN JY, JEON ES, CHO YH: Left heart decompression at venoarterial extracorporeal membrane oxygenation initiation in cardiogenic shock: prophylactic versus therapeutic strategy. J Thorac Dis 11: 3746-3756, 2019. https://doi.org/10.21037/jtd.2019.09.35

OŠŤÁDAL B, VÍZEK M: Patologická Fyziologie Srdce a Cév. Karolinum, Prague, 2005, 168 p.

OŠŤÁDAL P, BĚLOHLÁVEK J, BALÍK M, ŘÍHA H: Extracorporeal Membrane Oxygenation - Manual for Use in Adult Patients. Maxdorf, Prague, 2018, 95 p. 
OSTADAL P, MLCEK M, GORHAN H, SIMUNDIC I, STRUNINA S, HRACHOVINA M, KRUGER A, VONDRAKOVA D, JANOTKA M, HALA P, MATES M, OSTADAL M, LEITER JC, KITTNAR O, NEUZIL P: Electrocardiogram-synchronized pulsatile extracorporeal life support preserves left ventricular function and coronary flow in a porcine model of cardiogenic shock. PLoS One 13: e0196321, 2018. https://doi.org/10.1371/journal.pone.0196321

OSTADAL P, MLCEK M, KRUGER A, HALA P, LACKO S, MATES M, VONDRAKOVA D, SVOBODA T, HRACHOVINA M, JANOTKA M, PSOTOVA H, STRUNINA S, KITTNAR O, NEUZIL P: Increasing venoarterial extracorporeal membrane oxygenation flow negatively affects left ventricular performance in a porcine model of cardiogenic shock. J Transl Med 13: 266, 2015. https://doi.org/10.1186/s12967-015-0634-6

OSTADAL P, MLCEK M, STRUNINA S, HRACHOVINA M, KRUGER A, VONDRAKOVA D, JANOTKA M, HALA P, KITTNAR O, NEUZIL P: Novel porcine model of acute severe cardiogenic shock developed by upper-body hypoxia. Physiol Res 65: 711-715, 2016. https://doi.org/10.33549/physiolres.933294

PACKER M: The neurohormonal hypothesis: a theory to explain the mechanism of disease progression in heart failure. J Am Coll Cardiol 20: 248-254, 1992. https://doi.org/10.1016/0735-1097(92)90167-1

PEEK GJ, FIRMIN RK: The inflammatory and coagulative response to prolonged extracorporeal membrane oxygenation. ASAIO J 45: 250-263, 1999. https://doi.org/10.1097/00002480-199907000-00003

POPKOVÁ M, KURIŠČÁK E, HÁLA P, JANÁK D, TEJKL L, BĚLOHLÁVEK J, OŠŤÁDAL P, NEUŽIL P, KITTNAR O, MLČEK M: Increasing veno-arterial extracorporeal membrane oxygenation flow reduces electrical impedance of the lung regions in porcine acute heart failure. Physiol Res 69: 609-620, 2020. https://doi.org/10.33549/physiolres.933532

POWER JM, TONKIN AM: Large animal models of heart failure. Aust N Z Med 29: 395-402, 1999. https://doi.org/10.1111/j.1445-5994.1999.tb00734.x

PRANIKOFF T, HIRSCHL RB, STEIMLE CN, ANDERSON HL 3RD, BARTLETT RH: Efficacy of extracorporeal life support in the setting of adult cardiorespiratory failure. ASAIO J 40: M339-M343, 1994. https://doi.org/10.1097/00002480-199407000-00020

ELSO. Extracorporeal Life Support Registry Report. International Summary. Available online: https://www.elso.org/Registry/Statistics/ published January 30, 2020.

RIHAL CS, NAIDU SS, GIVERTZ MM, SZETO WY, BURKE JA, KAPUR NK, KERN M, GARRATT KN, GOLDSTEIN JA, DIMAS V, TU T: 2015 SCAI/ACC/HFSA/STS Clinical Expert Consensus Statement on the Use of Percutaneous Mechanical Circulatory Support Devices in Cardiovascular Care (Endorsed by the American Heart Association, the Cardiological Society of India, and Sociedad Latino Americana de Cardiologia Intervencion; Affirmation of Value by the Canadian Association of Interventional CardiologyAssociation Canadienne de Cardiologie d'intervention). J Card Fail 21: 499-518, 2015. https://doi.org/10.1016/j.cardfail.2015.03.002

ROBINSON SG: Indications and contraindications for ECLS in children with respiratory failure. In: Extracorporeal Life Support: The ELSO Red Book (5th Edition). BROGAN TV, LEQUIER L, LORUSSO R, MACLAREN G, PEEK G (eds), Ann Arbor, MI, USA, ELSO, 2017, pp 239-245.

ROZENCWAJG S, HEINSAR S, SUEN J, BASSI GL, MALFERTHEINER M, VERCAEMST L, BROMAN LM, SCHMIDT M, COMBES A, RATSEP I, FRASER JF, MILLAR JE, EUROPEAN EXTRACORPOREAL LIFE SUPPORT ORGANISATION INNOVATIONS W, THE NATIONAL HEALTH MEDICAL RESEARCH COUNCIL AUSTRALIA CENTRE OF RESEARCH EXCELLENCE FOR ADVANCED CARDIO-RESPIRATORY THERAPIES IMPROVING ORGAN S: Heart failure supported by veno-arterial extracorporeal membrane oxygenation (ECMO): a systematic review of pre-clinical models. Intensive Care Med Exp 8: 16, 2020. https://doi.org/10.1186/s40635-020-00303-5

SCHMITTO JD, MOKASHI SA, CHEN FY: Letter by Schmitto et al regarding article "Large animal models of heart failure: a critical link in the translation of basic science to clinical practice". Circ Heart Fail 3: e3; author reply e4, 2010. https://doi.org/10.1161/circheartfailure.109.930149

SCHMITTO JD, MOKASHI SA, LEE LS, POPOV AF, COSKUN KO, SOSSALLA S, SOHNS C, BOLMAN RM 3RD, COHN LH, CHEN FY: Large animal models of chronic heart failure (CHF). J Surg Res 166: 131-137, 2011. https://doi.org/10.1016/j.jss.2009.11.737 
SEIB PM, FAULKNER SC, ERICKSON CC, VAN DEVANTER SH, HARRELL JE, FASULES JW, FRAZIER EA, MORROW WR: Blade and balloon atrial septostomy for left heart decompression in patients with severe ventricular dysfunction on extracorporeal membrane oxygenation. Catheter Cardiovasc Interv 46: 179-186, 1999. https://doi.org/10.1002/(sici)1522-726x(199902)46:2<179::aid-ccd13>3.0.c0;2-w

SEO T, ITO T, IIO K, KATO J, TAKAGI H: Experimental study on the hemodynamic effects of veno-arterial extracorporeal membrane oxygenation with an automatically driven blood pump on puppies. Artif Organs 15 : 402-407, 1991.

SHEN I, LEVY FH, BENAK AM, ROTHNIE CL, O'ROURKE PP, DUNCAN BW, VERRIER ED: Left ventricular dysfunction during extracorporeal membrane oxygenation in a hypoxemic swine model. Ann Thorac Surg 71: 868-871, 2001. https://doi.org/10.1016/s0003-4975(00)02281-5

SHEN I, LEVY FH, VOCELKA CR, O'ROURKE PP, DUNCAN BW, THOMAS R, VERRIER ED: Effect of extracorporeal membrane oxygenation on left ventricular function of swine. Ann Thorac Surg 71: 862-867, 2001. https://doi.org/10.1016/s0003-4975(00)02280-3

SIDEBOTHAM D, ALLEN S, MCGEORGE A, BECA J: Catastrophic left heart distension following initiation of venoarterial extracorporeal membrane oxygenation in a patient with mild aortic regurgitation. Anaesth Intensive Care 40: 568-569, 2012.

SINGH A, LARIBI S, TEERLINK JR, MEBAZAA A: Agents with vasodilator properties in acute heart failure. Eur Heart J 38: 317-325, 2017. https://doi.org/10.1093/eurheartj/ehv755

SOLEIMANI B, PAE WE: Management of left ventricular distension during peripheral extracorporeal membrane oxygenation for cardiogenic shock. Perfusion 27: 326-331, 2012. https://doi.org/10.1177/0267659112443722

STRUNINA S, OSTADAL P: Left ventricle unloading during veno-arterial extracorporeal membrane oxygenation. Curr Res Cardiol 1: 5-8, 2016. https://doi.org/10.4172/2368-0512.1000054

SUGA H: Total mechanical energy of a ventricle model and cardiac oxygen consumption. Am J Physiol 236: H498-H505, 1979. https://doi.org/10.1152/ajpheart.1979.236.3.h498

SWOL J, BELOHLAVEK J, HAFT JW, ICHIBA S, LORUSSO R, PEEK GJ: Conditions and procedures for in-hospital extracorporeal life support (ECLS) in cardiopulmonary resuscitation (CPR) of adult patients. Perfusion 31: 182-188, 2016. https://doi.org/10.1177/0267659115591622

THIAGARAJAN RR, BARBARO RP, RYCUS PT, MCMULLAN DM, CONRAD SA, FORTENBERRY JD, PADEN ML: Extracorporeal Life Support Organization Registry International Report 2016. ASAIO J 63: 60-67, 2017. https://doi.org/10.1097/mat.0000000000000475

TOISCHER K, ROKITA AG, UNSOLD B, ZHU W, KARARIGAS G, SOSSALLA S, REUTER SP, BECKER A, TEUCHER N, SEIDLER T, GREBE C, PREUSS L, GUPTA SN, SCHMIDT K, LEHNART SE, KRUGER M, LINKE WA, BACKS J, REGITZ-ZAGROSEK V, SCHAFER K, FIELD LJ, MAIER LS, HASENFUSS G: Differential cardiac remodeling in preload versus afterload. Circulation 122: 993-1003, 2010. https://doi.org/10.1161/circulationaha.110.017566

TOOMASIAN JM, VERCAEMST L, BOTTRELL S, HORTON SB. The circuit. In: Extracorporeal Life Support: The ELSO Red Book (5th Edition). BROGAN TV, LEQUIER L, LORUSSO R, MACLAREN G, PEEK G (eds), Ann Arbor, MI, ELSO, 2017, pp 49-75.

TRAHANAS JM, WITER LJ, ALGHANEM F, BRYNER BS, IYENGAR A, HIRSCHL JR, HOENERHOFF MJ, POTKAY JA, BARTLETT RH, ROJAS-PENA A, OWENS GE, BOCKS ML: Achieving 12 hour normothermic ex situ heart perfusion: an experience of 40 porcine hearts. ASAIO J 62: 470-476, 2016. https://doi.org/10.1097/mat.0000000000000382

TRUBY LK, TAKEDA K, MAURO C, YUZEFPOLSKAYA M, GARAN AR, KIRTANE AJ, TOPKARA VK, ABRAMS D, BRODIE D, COLOMBO PC, NAKA Y, TAKAYAMA H: Incidence and implications of left ventricular distention during venoarterial extracorporeal membrane oxygenation support. ASAIO J 63: 257-265, 2017. https://doi.org/10.1097/mat.0000000000000553

VOLPE M, CARNOVALI M, MASTROMARINO V: The natriuretic peptides system in the pathophysiology of heart failure: from molecular basis to treatment. Clin Sci (Lond) 130: 57-77, 2016. https://doi.org/10.1042/cs20150469

WERDAN K, GIELEN S, EBELT H, HOCHMAN JS: Mechanical circulatory support in cardiogenic shock. Eur Heart J 35: 156-167, 2014. https://doi.org/10.1093/eurheartj/eht248 